\title{
Scholarly Societies and Scholarly Communication: A Look Ahead
}

\section{Roger C. Schonfeld}

In many academic and professional fields, the society-sponsored journal has for a century had a unique position in scholarly discourse. An annual meeting and conference provided intellectual exchange and social stimulation, while the journal provided a more formal mechanism to communicate, to review, to evaluate, and to certify. In celebrating the rich contributions $C E R L$ has made over the past 75 years, we find ourselves in a moment of profound change in the ways that scholarship is conducted and communicated. These changes in scholarly production and distribution, combined with a growing diversity in how research itself is conducted, provide CERL new opportunities to maintain its leadership position in the library field. The 75th anniversary of the journal is an opportune time for a bold examination of how ACRL and CERL can continue to facilitate the scholarship of librarianship. ${ }^{1}$

$C E R L$ has pursued a number of strategic decisions with real implications for its role in the community, including the shift to an open-access publishing model, the partnership with a third-party platform provider for its distribution infrastructure, and the cessation of its print version. Moving CERL to the HighWire platform infrastructure modernized discoverability and usability while spreading the cost of developing new features across a broader base of publishers and publications (although it is not without its risks). ${ }^{2}$ Moving to open access makes it possible for the core content of the journal to reach an unrestricted audience, which should allow for thinking about expanding readership and developing new audiences. And the elimination of print affords opportunities to begin reimagining the periodicity of the journal and the type of content it contains, including the nature of the article itself. These are major steps that, if seized effectively, can reposition $C \mathcal{E} R L$ in a variety of ways that make it a vanguard of professional communications for academic librarians.

At the same time, the environment for publishing on library-related issues has not been static. Several new publications have been developed, such as portal: Libraries and the Academy and In the Library with the Lead Pipe, the former published by Johns Hopkins University Press with an emphasis on technology, academic partnerships, and institutional missions, the latter self-hosted and focusing on "libraries and library workers" with an emphasis on their potential for community transformation. ${ }^{3}$ The editorial board of the Journal of Library Administration resigned amid concerns about the inability for authors to retain certain rights without requiring fees charged to them. ${ }^{4}$ In addition, a number of library-related organizations, including CLIR, OCLC, and my own Ithaka $S+R$, have maintained or developed publishing programs of their own, typically anchored by a series of research reports in addition to perspective pieces, newsletters, blogs, and other formats, with both staff and guest authorship. Journalism

Roger C. Schonfeld is Director, Library and Scholarly Communication Program at Ithaka S+R; e-mail: Roger.Schonfeld@ithaka.org. (C) 2015 Roger C. Schonfeld, Attribution-NonCommercial (http://creativecommons.org/licenses/by-nc/3.0/) CC BY-NC. 
about academic libraries and for academic librarians is provided principally by Library Journal (and its affiliated InfoDocket) and American Libraries, with some relevant coverage from Information Today, Inside Higher Ed, and The Chronicle of Higher Education. More recently, an engaged community of bloggers, some affiliated with these periodicals and even more independent of them, provides immediate perspective and analysis. These are some of the key factors that have led to a growing diffuseness in the publishing environment for the academic librarian community. ${ }^{5}$

Lorcan Dempsey and Scott Walter have argued that the field needs what they call a "platform publication" and that CERL would be "the most natural place to start." They suggest examples such as EDUCAUSE Review or Nature. ${ }^{6}$ They are right to push $C \mathcal{E R L}$ to see if it can claim a broader role in a changing landscape, especially given the full portfolio of publications that ACRL and its sections, interest groups, and chapters sponsor and support. In the context of the full spectrum of scholarly communication work of professional and scholarly societies, there is much opportunity.

One cannot consider a professional society's publishing program in isolation, given that so many changes are developing in other areas where societies traditionally exert leadership for their field. To take one example, almost all societies run some kind of annual meeting, which in many cases is a vital source of revenue for the society. Such a meeting typically includes business meetings, conference sessions, exhibits, job interviews, and a variety of other programming and social activities. The conference sessions and other programming are an essential component of current awareness and are typically an important part of the field's scholarly communication. At this point, the ALA and ACRL conferences do not demonstrate an obvious downward trend in terms of overall attendance figures, ${ }^{7}$ but new technologies and travel budget constraints are combining to yield a combination of pressure on and innovation for the traditional conference model. For a decade, ACRL itself has been offering a virtual conference option accompanying its traditional biennial event. Combining a limited amount of live-streaming with an extensive series of slidecasts, this format offers much of the content with little of the interactivity of the conference itself, a sort of virtual conference proceedings in a more native format. ${ }^{8}$

Recognizing this changing context for professional communication among academic librarians and for academic library issues, I would like to suggest a number of specific issues for consideration. While many such issues may cross beyond the boundaries of $C \mathcal{E} R L$, the strength of a journal is that it has an editor and an editorial board that provide the continuity needed for strategic planning and investment over time. Thus, these considerations are framed as being for CERL more so than ACRL broadly, even though a range of partnerships and organizational arrangements might be used to explore and in some cases realize these possibilities.

The audience it intends to reach and the impact it hopes to have. The shift to open access is a clear indication that $C \mathcal{E} R L$ wishes to reach an audience beyond its own members. ${ }^{9}$ This includes academic librarians, of course, but it also opens up the possibility to seek a broader audience, presumably in support of academic library issues and priorities. The New England Journal of Medicine, for example, has developed a series of "quick takes," animated overviews of recent research. Some of these appear to be designed for an audience of clinicians, such as one providing evidence to help guide responses to in-flight medical emergencies, while others might even have relevance for a mass audience, such as one on the risks associated with salt consumption. ${ }^{10}$ Are there audiences beyond ACRL's membership that $C \mathcal{E} R L$ should be mindfully trying to reach via its own platform or otherwise? For example, academic librarians have much to share with faculty members and academic leaders on topics such as data analytics, personal information and privacy, discovery, personal collections management, and the 
future of print collections. Is there a format that $C \mathcal{E} R L$ could adopt that would allow it to play some kind of translational role on behalf of its members to these audiences on topics such as these?

Serving member-authors. Many more ACRL members write and publish than CERL and the society's other journals have space to accommodate. With the new digital-only model, there will still be constraints on what CERL can vet and publish in traditional ways. At the same time, the development of platform "journals" such as PLoS One and suites of related journals such as those offered by Nature have suggested that other directions might be possible and perhaps even desirable. ${ }^{11}$ Could ACRL, perhaps using the $C E R L$ brand, serve as the platform for a larger share of the academic library literature? Could it provide vetting services, some if not all of which would differ from traditional peer review, for a larger share of the academic library literature? Could it knit together some of the scholarly communication and professional development activities across the various ACRL sections, interest groups, and chapters, and outside publications as well, in a way that would make them more discoverable, accessible, and valuable? ${ }^{12}$

Journalism. Keeping a community apprised of the latest developments that could be relevant to its professional practices is a valuable role that is richly complementary with scholarly communication, but the news sources that cover issues relevant to academic librarians have their shortcomings. To take one example, over the past year Nature has been covering discovery issues for the scientific community better than any other news service, but too few academic librarians see this valuable coverage ${ }^{13} C \mathcal{E} R L$ News and ACRL Update focus more on news about the association and its members, including articles and essays detailing projects and sharing perspectives, than it does on journalistic coverage of the broad range of issues relevant to the field of academic librarianship. ${ }^{14}$ Relevant journalism labors in many cases under limited resources, often adopting advertiser-driven models that either can yield potential conflicts when there are a small number of major display advertisers or can yield a tendency toward the controversial under click-driven models. Should ACRL undertake strong independent news coverage, perhaps delivered as a section in CERL or CERL News (similar to the practice for Nature)? Or should ACRL somehow feature an immediate and broad roundup of the relevant journalism conducted elsewhere?

Scoping the field. American academic librarianship does not stand in isolation. OCLC studies libraries and collections worldwide and across all library types, with the Research Library Partnership leading to an emphasis on the needs of large academic and research libraries. At Ithaka $S+R$, we try to serve the needs of scholarly research and higher learning in an integrated way, focusing not only on libraries and scholarly communication but also on educational transformation more broadly. Should ACRL and $C \mathcal{E} R L$ especially think about the definition of the field it seeks to cover as broader than has been done to date?

Discovery. While academic librarians continue to invest in discovery services to support their communities, there are probably some focused opportunities to support the discovery needs of academic librarians. One real weakness in library school programs and later-career professional development is the inability to refer to review articles for teaching purposes. In some fields, PhD students are frequently asked to write a review article as a major undertaking that provides a thoughtful and at times pointed distillation of the current state of knowledge and practice in a key segment of the field. Would such a format be appropriate for our field, and, if so, should CERL host it? ${ }^{15}$ Separately, the fragmented dialogue between academic librarians and scholarly publishers, campus academic leaders, and even in some cases academic faculty members, can be addressed in part as a discovery issue. Framed in this way, how can CERL help ACRL members discover the research and perspectives of related professions and communities? 
Research agendas. ACRL has promoted a number of important agendas in recent years. When it took an interest in documenting and increasing the value of the academic library, it commissioned a research review and eventually won funding to develop its Assessment in Action program, to strengthen campus competencies. ${ }^{16}$ Soon, this is expected to yield a special $C \mathcal{E} R L$ issue focusing on this current program. It may be impossible for $C \mathcal{E} R L^{\prime}$ 's coverage to be guided as directly by the type of research agenda that guides OCLC or Ithaka S+R. Still, it would be worth considering how the balance between special issues and regular issues, and other aspects of ACRL's publishing program, works to advance this type of agenda and the needs of the society's members. ${ }^{17}$

New formats. Finally, it is interesting to reflect upon what might be understood as the stubborn resilience of text, especially in the formal literature. Conference presentations are frequently captured as videos and uploaded to Vimeo or YouTube, and the underlying slide decks are shared natively or via SlideShare; as mentioned earlier, blogs and other forms of less traditional literature have flourished in our community. But a review of the literature shows regular citations of articles, reports, and other more formal writing, but much less frequent citation to slide decks, presentations, blog posts, and the like. Should CERL expand the set of formats that it publishes, allowing academic librarians' rigorous analytical and scholarly work to be formally certified in a peer-reviewed environment regardless of form?

There appear to be a number of new directions that $C \mathcal{E} R L$ can pursue in leading the scholarly dissemination and communications needed by ACRL members. All of the possibilities I have mentioned have implications for the business model of the journal and place new burdens on a group of volunteers who care for its continuation. CERL has been a valuable contribution to the profession over the last 75 years and, like all established institutions, must be continually reimagined to take full advantage of broader trends to meet evolving needs.

\section{Notes}

1. I am grateful to Scott Walter for proposing an essay on this topic. I also thank Lisa Hinchliffe, Kimberly Lutz, Deanna Marcum, and Stephanie Orphan for helpful comments and suggestions.

2. "HighWire Expands Library Coverage with ACRL Publications Online," Dec. 1, 2009, available online at http://highwire.stanford.edu/librarians/HWACRL_CHOICE.pdf [accessed 8 January 2015]. It remains to be seen what implications if any $C \mathcal{E} R L$ may face from HighWire's recent governance change. See Todd Carpenter, "HighWire Press Moves out of Stanford and Becomes an Equity-funded 'Inc.,'" The Scholarly Kitchen (June 2, 2014), available online at http:// scholarlykitchen.sspnet.org/2014/06/02/highwire-press-moves-out-of-stanford-and-becomes-anequity-funded-inc/ [accessed 8 January 2015]. For a general overview of some key issues facing professional society publishers in terms of online platforms, see Joseph Esposito, "The Inexorable Path of the Professional Society Publisher," The Scholarly Kitchen (May 8, 2013), available online at http://scholarlykitchen.sspnet.org/2013/05/08/the-inexorable-path-of-the-professional-societypublisher/ [accessed 8 January 2015].

3. See "Author Guidelines / Purpose," portal: Libraries and the Academy, available online at www.press.jhu.edu/journals/portal_libraries_and_the_academy/guidelines.html [accessed 8 January 2015] and "About / What We Do," In the Library with the Lead Pipe, available online at www.inthelibrarywiththeleadpipe.org/about/ [accessed 8 January 2015].

4. See Meredith Schwartz, "JLA Board Resigns Over Licensing Terms," Library Journal (Mar. 27, 2013), available online at http://lj.libraryjournal.com/2013/03/oa/jla-board-resigns-over-licensingterms/.

5. In fact, C\&RL has acknowledged that it faces "increasing competition to recruit the best work for publication, not just from established journals, but also from an array of new journals, blogs, and other venues for thoughtful discourse made possible by new publishing technologies." James Elmborg and Scott Walter, "Critical Thinking About 'Getting Research Published,"' College E Research Libraries 76 (Jan. 2015), 2, available online at http://dx.doi.org/10.5860/crl.76.1.2 [accessed 8 January 2015]. 
6. Lorcan Dempsey and Scott Walter, "A Platform Publication for a Time of Accelerating Change," College $\mathcal{E}$ Research Libraries 75 (Nov. 2014), 760-62, available online at http://dx.doi. org/10.5860/crl.75.6.760 [accessed 8 January 2015].

7. www.ala.org/conferencesevents/past/pastannualconferences [accessed 8 January 2015].

8. http://conference.acrl.org/virtual-conference-pages-161.php [accessed 8 January 2015].

9. Given that all ACRL members received a free print version as a benefit of membership, the rationale for moving to open access was making the journal "freely available online to all around the world" (in other words, seeking a broader audience). See the statement (available online) at www.acrl.ala.org/acrlinsider/archives/3255 [accessed 8 January 2015].

10. These animations are freely available online at http://www.youtube.com/ playlist?list=PLI8Ak-hj5dgEvzTkyS7P8qf7PfESVNedM [accessed 8 January 2015].

11. Dale Askey, “Is It Time for a PLoLIS?” Taiga Forum (Jan. 13, 2014), available online at http:// taiga-forum.org/is-it-time-for-a-plolis/ [accessed 8 January 2015].

12. I am grateful to Scott Walter for suggesting this latter possibility.

13. See, for example, Richard Van Noorden, "Online Collaboration: Scientists and the Social Network," Nature 512 (Aug. 14, 2014): 126-29, available online at http://dx.doi.org/10.1038/512126a [accessed 8 January 2015]; Elizabeth Gibney, "How to Tame the Flood of Literature," Nature 513 (Sept. 4, 2014): 129-30, available online at http://dx.doi.org/10.1038/513129a [accessed 8 January 2015]; Richard Van Noorden, "Google Scholar Pioneer on Search Engine's Future," Nature (Nov. 7, 2014), available online at http://dx.doi.org/10.1038/nature.2014.16269 [accessed 8 January 2015].

14. "Instructions for Authors," CERL News, available at http://crln.acrl.org/site/misc/author. $x h t m l$ [accessed 8 January 2015]. The column "In the News" often has valuable and helpful content but does not offer a comprehensive source of journalism for the field.

15. ACRL's "Keeping Up With..." series offers executive summaries on some of the types of issues that might also be suitable for a more extensive review treatment embedded in a more formalized channel. Linking the review essay with the "Keeping Up With..." executive summary could be quite powerful. See http://www.ala.org/acrl/publications/keeping_up_with [accessed 8 January 2015].

16. Association of College and Research Libraries. Value of Academic Libraries: A Comprehensive Research Review and Report. Researched by Megan Oakleaf. Chicago: Association of College and Research Libraries, 2010, available online at http://www.acrl.ala.org/value/?page_id=21 [accessed 8 January 2015]. See also http://www.ala.org/acrl/AiA [accessed 8 January 2015]. This endeavor has worked to build connections between librarians and other key campus constituents.

17. The special issues that $C \mathcal{E} R L$ is now offering with greater frequency pushes it more in the direction of Library Trends, the issues of which are generally organized around a single thematic topic. 